\title{
Crystallographic and DFT Studies on Pyrrolo[1,2-c]imidazole Scaffolds
}

\author{
Manikandan Jayaraman, ${ }^{1}$ Rajarathinam Balakrishnan, ${ }^{2}$ Kannan Muthu, ${ }^{1}$ \\ Manivel Panneerselvam, ${ }^{1}$ Vasuki Gnanasambandam, ${ }^{2}$ and Krishna Ramadas ${ }^{1}$ \\ ${ }^{1}$ Centre for Bioinformatics, Pondicherry University, Puducherry 605014, India \\ ${ }^{2}$ Department of Chemistry, Pondicherry University, Puducherry 605014, India
}

Correspondence should be addressed to Vasuki Gnanasambandam; vasukig@gmail.com and Krishna Ramadas; krishstrucbio@gmail.com

Received 30 October 2013; Accepted 17 February 2014; Published 14 April 2014

Academic Editor: Abdul Razak Ibrahim

Copyright (C) 2014 Manikandan Jayaraman et al. This is an open access article distributed under the Creative Commons Attribution License, which permits unrestricted use, distribution, and reproduction in any medium, provided the original work is properly cited.

The crystal structures of the compounds $\mathrm{C}_{15} \mathrm{H}_{14} \mathrm{~N}_{4} \mathrm{O}_{2}(1)$ and $\mathrm{C}_{16} \mathrm{H}_{16} \mathrm{~N}_{4} \mathrm{O}_{4}$ (2) are reported and analyzed by single crystal X-ray diffraction technique. Compounds (1) and (2) crystallized in monoclinic space group P21/c and Cc with four molecules in the unit cell, respectively. The unit cell parameters for compound (1) are $a=11.4501(15) \AA, b=9.7869(11) \AA, c=12.3653(15) \AA, \beta=90.997(11)^{\circ}$, and Volume $=1385.5(3) \AA^{3}$ and for compound (2) are $a=13.865(2) \AA, b=6.9538(8) \AA, c=16.841(2) \AA, \beta=98.602(11)^{\circ}$, and Volume $=1605.4(4) \AA^{3}$. In both compounds (1) and (2), the pyrrolidine ring adopts half-chair conformation. Moreover, both inter- and intramolecular $\mathrm{N}-\mathrm{H} \cdots \mathrm{O}$ hydrogen bonds stabilize the crystal structure and play a crucial role in crystal packing. This intermolecular interaction alone constructs $\mathrm{C}_{1}{ }^{1}$ chain motif in both compounds. It is also supported by weak intermolecular $\pi-\pi$ interaction which is essential for the stability of the crystal packing. Further, the Density Functional Theory (B3LYP) method with standard 6-31G basis set was used in the calculation and calculated geometrical parameter is correlated with the corresponding experimental data. The obtained HOMO and LUMO energies are in negative values indicating that the compounds are in stable state.

\section{Introduction}

The five-membered heterocyclic pyrrolidine ring system commonly occurs in many natural products and these five members are leading components of alkaloids [1]. They are essential synthetic components of HIV reverse transcriptase enzyme and inhibitors of substance P neurotransmitters [2, 3]. Further, they also act as antibacterial and antiamnestic agents $[4,5]$. The heterocyclic imidazole derivatives are also considered to be an important synthetic precursor in drug designing and discovery process $[6,7]$. These imidazole derivatives have antitumor, antimicrobial, and antiinflammatory activity and they also inhibit MAP kinase p38 protein [8]. Also, the novel Py-Im derivatives have been established as powerful partial agonists of the $\alpha 1 \mathrm{~A}$ adrenoceptor (GPCR known as adrenergic receptor) and have shown better response over the $\alpha 1 \mathrm{~B}, \alpha 1 \mathrm{D}$, and $\alpha 2 \mathrm{~A}$ receptor subtypes [9]. The fused Py-Im derivative also inhibits the JNK (c-Jun$\mathrm{N}$-terminal kinase) pathway which is the fascinating drug target for several neurodegenerative disorders. In view of the growing biological importance of Py-Im derivatives, the single crystal X-ray diffraction studies on the compounds were carried out and analyzed.

\section{Experimental}

2.1. Synthesis. Synthesis of (trans-7,7a)-5-Amino-2-methyl-1,3dioxo-7-(p-tolyl)-2,3,7,7a-tetrahydro-1H-pyrrolo[1,2-c]imidazole-6-carbonitrile: Compound (1). 3-Methylhydantoin (342 mg, $3 \mathrm{mmol}$ ), malononitrile (198 mg, $3 \mathrm{mmol}$ ), 4-methylbenzaldehyde $(0.35 \mathrm{~mL}, 3 \mathrm{mmol})$, piperidine $10 \mathrm{mmol} \%$ and $25 \mathrm{~mL}$ of water were stirred in a $50 \mathrm{~mL} \mathrm{RB}$ flask for $3 \mathrm{~h}$ at $70^{\circ} \mathrm{C}$. The solid which separated from the reaction mixture was filtered and washed with hexane/ethylacetate mixture $(8: 2$ ratio, $20 \mathrm{~mL}$ ). The pure product was characterized by FT-IR, $1 \mathrm{H}$ NMR, 13C NMR and HRMS data, which were all in good agreement with the assigned structure. The product was recrystallized from acetonitrile solvent [10]. 
TABLE 1: Crystal data and structure refinement summary of compounds (1) and (2).

\begin{tabular}{|c|c|c|}
\hline Identification code & 1 & 2 \\
\hline Empirical formula & $\mathrm{C}_{15} \mathrm{H}_{14} \mathrm{~N}_{4} \mathrm{O}_{2}$ & $\mathrm{C}_{16} \mathrm{H}_{16} \mathrm{~N}_{4} \mathrm{O}_{4}$ \\
\hline Formula weight & 282.3 & 328.33 \\
\hline Temperature/K & $293(2)$ & $293(2)$ \\
\hline Wavelength & $0.71073 \AA$ & $0.71073 \AA$ \\
\hline Crystal system & Monoclinic & Monoclinic \\
\hline Space group & $\mathrm{P} 2{ }_{1} / \mathrm{c}$ & $\mathrm{Cc}$ \\
\hline$a / \AA$ & $11.4501(15)$ & $13.865(2)$ \\
\hline$b / \AA$ & $9.7869(11)$ & $6.9538(8)$ \\
\hline$c / \AA$ & $12.3653(15)$ & $16.841(2)$ \\
\hline$\beta /^{\circ}$ & $90.997(11)$ & $98.602(11)$ \\
\hline Volume $/ \AA^{3}$ & $1385.5(3)$ & $1605.4(4)$ \\
\hline$Z$ & 4 & 4 \\
\hline$\rho_{\text {calc }} \mathrm{Mg} / \mathrm{mm}^{3}$ & 1.353 & 1.358 \\
\hline$\mu / \mathrm{mm}^{-1}$ & 0.09 & 0.10 \\
\hline$F(000)$ & 592.0 & 688.0 \\
\hline Crystal size $/ \mathrm{mm}^{3}$ & $0.3 \times 0.25 \times 0.1$ & $0.5 \times 0.4 \times 0.1$ \\
\hline$\theta$ range for data collection $\left(^{\circ}\right)$ & 3.9 to 29.1 & 3.7 to 47.5 \\
\hline Index ranges & $-11 \leq h \leq 13,-11 \leq k \leq 11,-13 \leq l \leq 14$ & $-16 \leq h \leq 16,-8 \leq k \leq 8,-16 \leq l \leq 20$ \\
\hline Reflections collected & 7461 & 4242 \\
\hline Independent reflections & $2431[R(\mathrm{int})=0.039]$ & $2195[R(\mathrm{int})=0.041]$ \\
\hline Data/restraints/parameters & $3233 / 0 / 192$ & $3071 / 2 / 221$ \\
\hline$S$ (=goodness-of-fit on $F^{2}$ ) & 1.02 & 1.19 \\
\hline Final $R$ indexes $[I \geq 2 \sigma(I)]$ & $R_{1}=0.044, w R_{2}=0.1237$ & $R_{1}=0.058, w R_{2}=0.2495$ \\
\hline Largest difference peak/hole/e $\AA^{-3}$ & $0.17 /-0.15$ & $0.40 /-0.34$ \\
\hline
\end{tabular}

Synthesis of (trans-7,7a)-5-Amino-7-(3,4-dimethoxyphenyl)-2methyl-1,3-dioxo-2,3,7,7a-tetrahydro-1H-pyrrolo[1,2-c]imidazole-6-carbonitrile: Compound (2). 3-Methylhydantoin(342 mg, $3 \mathrm{mmol}$ ), malononitrile (198 mg, $3 \mathrm{mmol}), 3$,4-dimethoxy benzaldehyde (500 $\mathrm{mg}, 3 \mathrm{mmol}$ ), piperidine $10 \mathrm{mmol} \%$ and $25 \mathrm{~mL}$ of water were stirred in a $50 \mathrm{~mL} \mathrm{RB}$ flask for $3 \mathrm{~h}$ at $70^{\circ} \mathrm{C}$. The solid which separated from the reaction mixture was filtered and washed with hexane/ethylacetate mixture $(8: 2$ ratio, $20 \mathrm{~mL})$. The pure product was characterized by FT-IR, 1H NMR, 13C NMR and HRMS data, which were all in good agreement with the assigned structure. The product was recrystallized from acetonitrile solvent [10].

2.2. Crystallographic Data Collection and Refinement. Colorless plate shape single crystals with dimensions of $0.3 \times 0.25 \times$ $0.1 \mathrm{~mm}(1)$ and $0.5 \times 0.4 \times 0.1 \mathrm{~mm}(2)$ were selected and X-ray data were collected on a Xcalibur, Eos diffractometer, using CrysAlisPro software and graphite-monochromated Mo-k $\alpha$ $(\lambda=0.7107 \AA)$ at $298 \mathrm{~K}$. The structures were solved by direct methods using SHELXS-97 [11] and refined by SHELXL-97 [11] with the full-matrix least square procedure. For data collection, data reduction, and space group determination of compounds, CrysAlisPro [12] software was used. All of the nonhydrogen atoms were refined anisotropically while the hydrogen atoms were refined isotropically. $\mathrm{H}$ atoms were positioned geometrically and allowed to ride on their parent atoms, with $d(\mathrm{~N}-\mathrm{H})=0.86 \AA, d(\mathrm{C}-\mathrm{H})=0.93 \AA$ for $\mathrm{CH}$ and aromatic and $0.96 \AA$ for $\mathrm{CH}_{3}$ atoms. The $\mathrm{U}_{\text {iso values were }}$ constrained to be $1.5 \mathrm{U}_{\mathrm{eq}}$ of the carrier atom for methyl $\mathrm{H}$ atoms and $1.2 \mathrm{U}_{\mathrm{eq}}$ for the remaining $\mathrm{H}$ atoms. By using ORTEP [13] and Platon [14] programs, thermal ellipsoid and crystal packing diagrams were created. Mercury [15] program was used for analyzing the hydrogen bonding graphset motif.

2.3. Computational Details. The molecular structures of compounds (1) and (2) were subjected to quantum chemical density functional calculation with Jaguar software package using the Becke-3Lee-Yang-Parr (B3LYP) hybrid functional with the standard 6-31G(TM) ${ }^{* *+}(6 \mathrm{D})$ basis set $\left({ }^{* *}\right.$ indicates that it places polarization functions on all atoms except for transition metals, + option places diffuse function on all atoms except $\mathrm{H}$ and $\mathrm{He}$, and $6 \mathrm{D}$ represents $\mathrm{d}$ shells including the six Cartesian $\mathrm{d}$ functions $\mathrm{d}_{x} 2, \mathrm{~d}_{y} 2, \mathrm{~d}_{z} 2, \mathrm{~d}_{x y}, \mathrm{~d}_{x z}$, and $\mathrm{d}_{y z}$ ) used to calculate the HOMO (highest occupied molecular orbital) and LUMO (lowest unoccupied molecular orbital) energy distribution and HOMO-LUMO energy gap.

\section{Results and Discussion}

The crystal data and structure refinement of compounds (1) and (2) were given in Table 1. The selected geometric parameters of compounds (1) and (2) were given in Table 2. Hydrogen bonds for the compounds (1) and (2) are listed in Table 3. The chemical structures for compounds are shown in Figure 1. The ORTEP diagram and graph-set motif of 


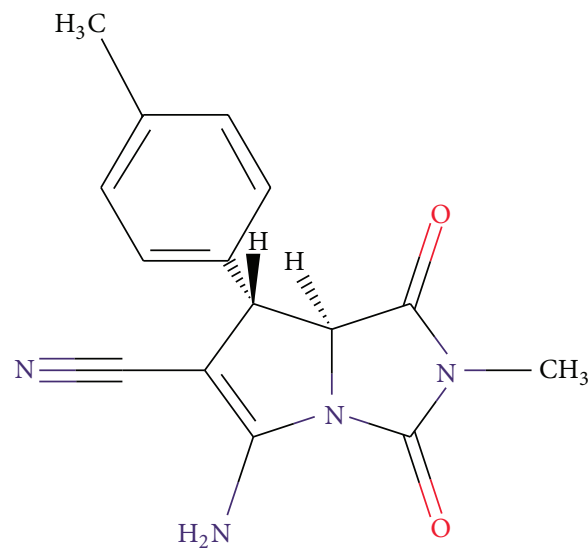

(a)

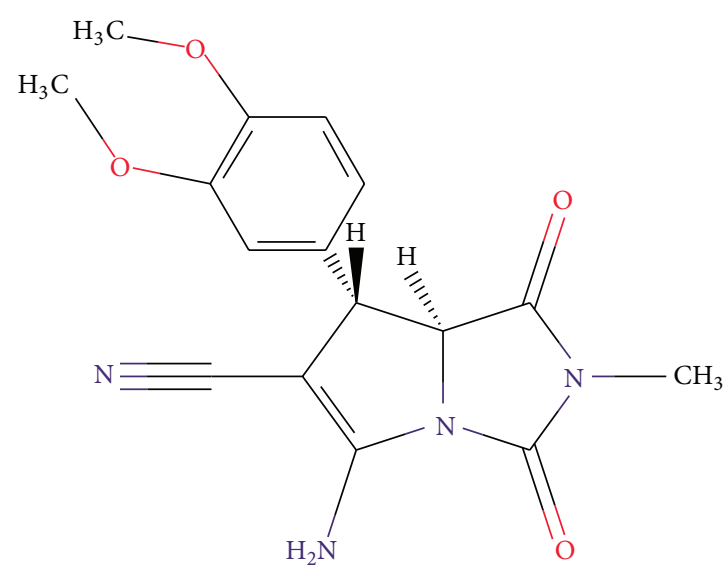

(b)

FIgURE 1: Chemical structures of compounds (1) and (2).

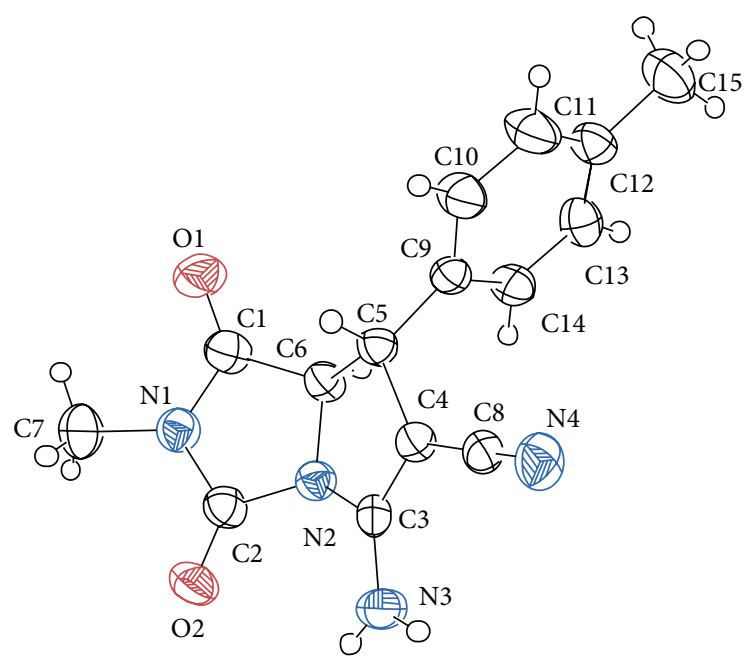

(a)

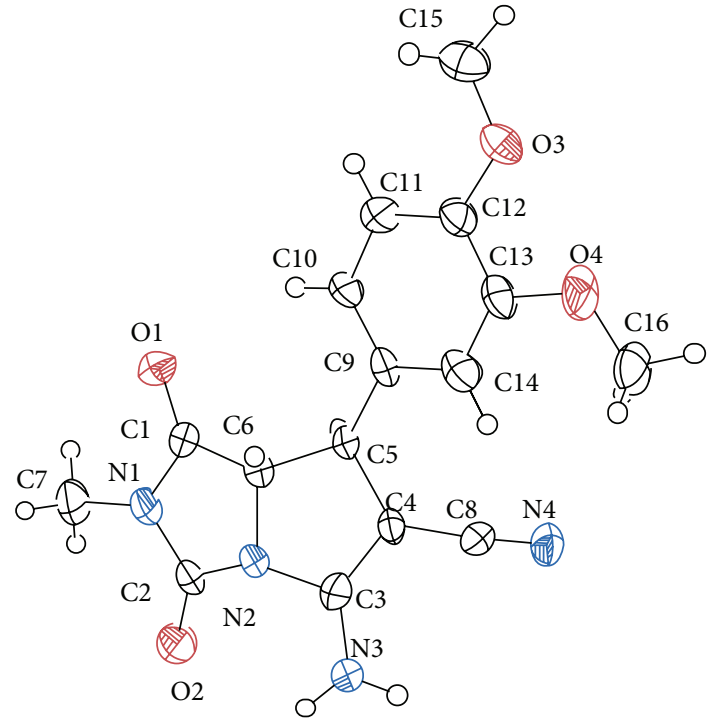

(b)

FIGURE 2: Molecular structures of compounds (1) and (2) with atom numbering scheme. Thermal ellipsoids shown at $50 \%$ probability level.

the compounds (1) and (2) are shown in Figures 2 and 3, respectively. Intermolecular $\mathrm{C}-\mathrm{H} \cdots \pi$ and $\pi-\pi$ interactions of the compounds are displayed in Figure 4.

3.1. Geometrical Parameters Analysis. Bond lengths of compounds (1) and (2) are in normal range [16] and showing average mean bond distances of $\mathrm{C}-\mathrm{C}=1.434 \AA, \mathrm{C}-\mathrm{O}=$ $1.205 \AA$ for compound (1) and $\mathrm{C}-\mathrm{C}=1.431 \AA, \mathrm{C}-\mathrm{O}=1.327 \AA$ for compound (2), respectively. In compound (1) the bond distances of $\mathrm{C} 1=\mathrm{O} 1$ and $\mathrm{C} 2=\mathrm{O} 2$ show $1.203(3)$ to $1.207(2) \AA$, respectively, whereas in compound (2) $\mathrm{C} 1=\mathrm{O} 1$ and $\mathrm{C} 2=\mathrm{O} 2$ distances vary from 1.217(7) to 1.199(7) $\AA$, respectively, which are comparable with the reported double bond lengths [17]. In addition to that, both compounds display the electron delocalization over the atoms of $\mathrm{C} 3-\mathrm{C} 4-\mathrm{C} 8$ between the amine and nitrile group. The nitrile $\mathrm{N} 4 \equiv \mathrm{C} 8$ bond length

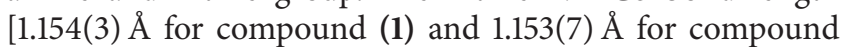

(2)] is the shortest $\mathrm{N}-\mathrm{C}$ bond and falls into the range of a triple bond [17], confirming the presence of the nitrile group. In both (1) and (2), the sum of bond angle around the N1 atom of the pyrrolidine ring [C1-N1-C2, C1-N1-C7, and C2-N1$\mathrm{C} 7=358.4(4)^{\circ}$ for compound (1) and $360.1(6)^{\circ}$ for compound (2)] indicates $\mathrm{sp}^{2}$ hybridization and the bond angle of $\mathrm{Cl}-$ $\mathrm{N} 1-\mathrm{C} 2, \mathrm{C} 6-\mathrm{N} 2-\mathrm{C} 3$, and $\mathrm{C11}-\mathrm{C} 12-\mathrm{C} 13$ deviates from $120^{\circ}$ due to the presence of substituents. The imidazole ring fused bisectionally with pyrrolidine ring at an angle of $42.74(11)^{\circ}$ for compound (1) and 47.3(3) for compound (2). In compounds (1) and (2), the benzene ring is planar [maximum deviation of $-0.0039 \AA$ and $-0.017 \AA$ ] and forms (+) syn-clinal and (+) syn-periplanar conformation with fused Py-Im ring with the dihedral angles of $68.4(2)^{\circ}$ for compound (1) and $2.2(7)^{\circ}$ for compound (2) [C4-C5-C9-C14], respectively. In compound (1), the methyl group attached to the p-tolyl is coplanar with benzene ring and forms $(-)$ antiperiplanar conformation 


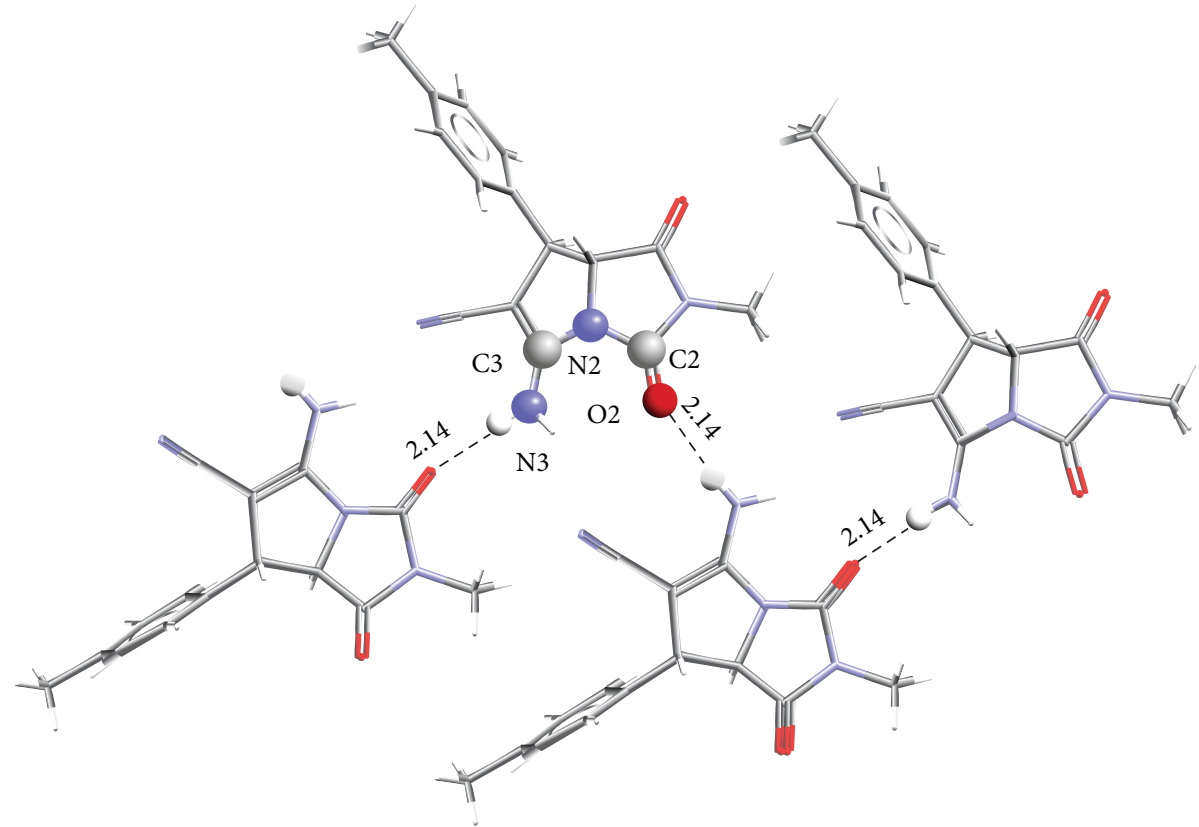

(a)

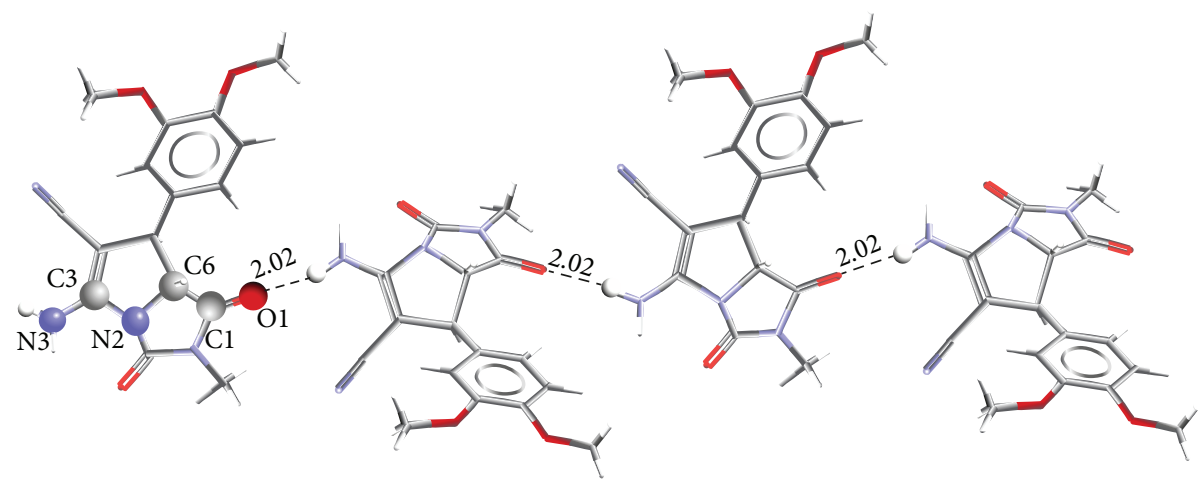

(b)

FIgURE 3: Intermolecular motif formed by N-H $\cdots$ O interaction shown with a bond distance $(\AA)$. (a) and (b) show $\mathrm{C}_{1}{ }^{1}(6)$ and $\mathrm{C}_{1}{ }^{1}(7)$ chain motif of compounds (1) and (2), respectively. Atoms involved in chain motif formation are shown in ball stick format.

$\left[\mathrm{C} 15-\mathrm{C} 12-\mathrm{C} 11-\mathrm{C} 10=-179.8(2)^{\circ}\right]$. However, two methoxy groups present in compound (2); the para-methoxy group is essentially coplanar with the attached benzene ring with the torsional angle of $\mathrm{C} 11-\mathrm{C} 12-\mathrm{O} 3-\mathrm{C} 15=2.6(9)^{\circ}$, whereas the meta-positioned methoxy is deviated from plane with the torsional angle of $\mathrm{C} 14-\mathrm{C} 13-\mathrm{O} 4-\mathrm{Cl}=-13.2(9)^{\circ}$ which subsequently forms $(+)$ and (-) syn-periplanar conformation, respectively.

3.2. Ring Puckering Analysis. Cremer and Pople ring puckering analysis is an essential criterion for understanding the shape and conformation of rings [18]. In compound (1), the five-membered imidazole ring [N1-C1-C6-N2-C2] adopts envelope conformation with the puckered atom N1 having the maximum of $-0.0621(18) \AA$ deviation and the puckering parameters $Q=0.098(2) \AA$ and $\Phi=179.1(12)^{\circ}$, whereas pyrrolidine ring [N2-C3-C4-C5-C6] adopts twisted half-chair
TABLE 2: Selected geometric parameters in compounds (1) and (2) $\left(\AA ̊\right.$ and $\left.^{\circ}\right)$.

\begin{tabular}{lcccc}
\hline $\begin{array}{l}\text { Bond lengths } \\
\text { and angles }\end{array}$ & (Exp.) & (Cal.) & (Exp.) & (Cal.) \\
\hline C1-C6 & $1.508(3)$ & 1.526 & $1.501(7)$ & 1.524 \\
C5-C6 & $1.545(3)$ & 1.566 & $1.552(7)$ & 1.567 \\
C1-O1 & $1.203(3)$ & 1.213 & $1.217(7)$ & 1.213 \\
C2-O2 & $1.207(2)$ & 1.218 & $1.199(7)$ & 1.218 \\
N1-C2 & $1.381(3)$ & 1.395 & $1.375(8)$ & 1.396 \\
N4-C8 & $1.154(3)$ & 1.168 & $1.153(7)$ & 1.168 \\
C1-N1-C2 & $112.4(16)$ & 112.4 & $111.5(4)$ & 112.4 \\
C1-N1-C7 & $124.0(2)$ & 124.4 & $125.2(5)$ & 124.2 \\
C2-N1-C7 & $121.9(2)$ & 122.7 & $123.3(5)$ & 123.0 \\
C6-N2-C3 & $109.3(19)$ & 109.2 & $108.2(7)$ & 109.1 \\
\hline
\end{tabular}

Exp.: experimental data; Cal.: calculated data $\left(6-31 \mathrm{G}(\mathrm{TM})^{* *+}(6 \mathrm{D})\right.$ basis set). 
TABLE 3: Hydrogen bond geometries of compounds (1) and (2) ( $\AA$ and $\left.^{\circ}\right)$.

\begin{tabular}{|c|c|c|c|c|c|}
\hline $\mathrm{D}-\mathrm{H} \cdots \mathrm{A}$ & $d(\mathrm{D}-\mathrm{H})$ & $d(\mathrm{H} \cdots \mathrm{A})$ & $d(\mathrm{D} \cdots \mathrm{A})$ & $<(\mathrm{DHA})$ & Symmetry equivalent \\
\hline \multicolumn{6}{|r|}{ 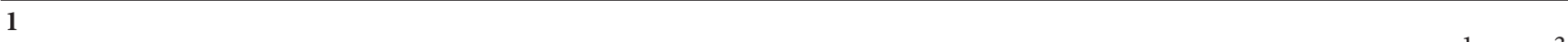 } \\
\hline $\mathrm{N}(3)-\mathrm{H}(3 \mathrm{~A}) \cdots \mathrm{O}(2)$ & 0.86 & 2.14 & $2.993(2)$ & 171 & $-x+1, y-\frac{1}{2},-z+\frac{3}{2}$ \\
\hline $\mathrm{N}(3)-\mathrm{H}(3 \mathrm{~B}) \cdots \mathrm{O}(2)$ & 0.86 & 2.54 & $2.999(2)$ & 115 & $x, y, z$ \\
\hline $\mathrm{N}(3)-\mathrm{H}(3 \mathrm{~B}) \cdots \mathrm{N}(4)$ & 0.86 & 2.38 & $3.125(2)$ & 146 & $-x+1, y+\frac{1}{2},-z+\frac{3}{2}$ \\
\hline \multicolumn{6}{|r|}{ 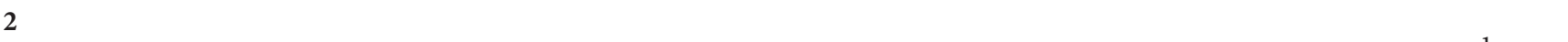 } \\
\hline $\mathrm{N}(3)-\mathrm{H}(3 \mathrm{~A}) \cdots \mathrm{O}(1)$ & 0.86 & 2.03 & $2.861(7)$ & 164 & $x, 1-y,-\frac{1}{2}+z$ \\
\hline $\mathrm{N}(3)-\mathrm{H}(3 \mathrm{~B}) \cdots \mathrm{N}(4)$ & 0.86 & 2.30 & $3.136(7)$ & 166 & $x, 1+y, z$ \\
\hline $\mathrm{C}(5)-\mathrm{H}(5) \cdots \mathrm{O}(4)$ & 0.98 & 2.52 & $3.455(6)$ & 159 & $-\frac{1}{2}+x, \frac{1}{2}+y, z$ \\
\hline $\mathrm{C}(7)-\mathrm{H}(7 \mathrm{~A}) \cdots \mathrm{O}(3)$ & 0.96 & 2.56 & $3.105(8)$ & 116 & $-\frac{1}{2}+x, \frac{3}{2}+y, z$ \\
\hline $\mathrm{N}(3)-\mathrm{H}(3 \mathrm{~B}) \cdots \mathrm{O}(2)$ & 0.86 & 2.60 & $3.011(7)$ & 111 & $x, y, z$ \\
\hline $\mathrm{C}(10)-\mathrm{H}(10) \cdots \mathrm{O}(1)$ & 0.93 & 2.59 & $3.352(8)$ & 140 & $x, y, z$ \\
\hline
\end{tabular}

conformation with the puckering parameters $Q=0.146(2) \AA$ and $\Phi=124.1(8)^{\circ}$. In case of compound (2), both pyrrolidine and imidazole rings adopt half-chair conformation with the puckering parameters $Q 1=0.082(5) \AA, \Phi 1=125(4)^{\circ}$, and $Q 2$ $=0.223(5) \AA, \Phi 2=126.4(14)^{\circ}$, respectively.

3.3. Intra- and Intermolecular Interactions and Crystal Packing Analysis. The crystal structures of compounds (1) and (2) are stabilized via intramolecular $\mathrm{N}-\mathrm{H}$... O hydrogen bond and intermolecular $\mathrm{C}-\mathrm{H} \cdots \mathrm{O}, \mathrm{N}-\mathrm{H} \cdots \mathrm{O}$, and $\mathrm{N}-\mathrm{H} \cdots \mathrm{N}$ hydrogen bonds. In addition, the packing is stabilized by special type of interaction such as $\mathrm{C}-\mathrm{H} \cdots \pi, \mathrm{C}-\mathrm{N} \cdots \pi$, and $\pi-\pi$ interactions. The crystal structure of compound (1) is stabilized by intramolecular N3-H3B $\cdots \mathrm{O} 2$ hydrogen bond, in which the amine N3 acts as a donor and makes hydrogen bond with carbonyl $\mathrm{O} 2$ with the bond length of 2.99(2) A. Further, the crystal packing is stabilized by two intermolecular N3-H3A... O 2 and N3-H3B . . N4 hydrogen bonds with the bond distances of 2.993(2) $\AA$ and 3.125(2) $\AA$, respectively. Intermolecular $\mathrm{N} 3-\mathrm{H} 3 \mathrm{~A} \cdots \mathrm{O} 2$ (symmetry code: $1-x,-1 / 2+y, 3 / 2-z)$ hydrogen bond generates chain $\mathrm{C}_{1}{ }^{1}$ (6) motif [19] with the bond length of $2.14 \AA$ (Figure 3(a)). N$\mathrm{H} \cdots \mathrm{N}$ (symmetry code: $1-x, 1 / 2+y, 3 / 2-z$ ) hydrogen bond formed between amine $\mathrm{N}$ and nitrile $\mathrm{N}$ group with a bond length of 3.125(2) $\AA$, whereas in compound (2), two intramolecular hydrogen bonds contribute to crystal packing such as $\mathrm{N} 3-\mathrm{H} 3 \mathrm{~B} \cdots \mathrm{O} 2$ and $\mathrm{C} 10-\mathrm{H} 10 \cdots \mathrm{O} 1$ with the bond distances of 3.011(7) and 3.354(8) $\AA$, respectively. Atoms O1 and $\mathrm{O} 2$ act as a hydrogen bond acceptor for $\mathrm{C}-\mathrm{H} \cdots \mathrm{O}[\mathrm{C} 10-$ $\mathrm{H} 10 \cdots \mathrm{O} 1]$ and $\mathrm{N}-\mathrm{H} \cdots \mathrm{O}[\mathrm{N} 3-\mathrm{H} 3 \mathrm{~B} \cdots \mathrm{O} 2]$ contacts. Additionally, there are four intermolecular hydrogen bonds which include $\mathrm{N} 3-\mathrm{H} 3 \mathrm{~A} \cdots \mathrm{O} 1$ (symmetry code: $x, 1-y,-1 / 2+z$ ), $\mathrm{N} 3-\mathrm{H} 3 \mathrm{~B} \cdots \mathrm{N} 4$ (symmetry code: $x, 1+y, z$ ), C5-H5 $\cdots \mathrm{O} 4$ (symmetry code: $-1 / 2+x, 1 / 2+y, z$ ), and C7-H7A $\cdots$ O3 (symmetry code: $-1 / 2+x, 3 / 2+y, z$ ) contributing to crystal packing. The intermolecular $\mathrm{N}-\mathrm{H} \cdots \mathrm{O}$ [N3-H3A-O1] hydrogen bond generates chain $\mathrm{C}_{1}{ }^{1}$ (7) motif [19] with the bond length of $2.02 \AA$ (Figure 3(b)).
TABLE 4: Calculated HOMO and LUMO energy value in compounds (1) and (2).

\begin{tabular}{lcc}
\hline \multirow{2}{*}{ Parameters } & \multicolumn{2}{c}{$\mathrm{B} 3 \mathrm{LYP} / 6-31 \mathrm{G}(\mathrm{TM})^{* *+}(6 \mathrm{D})$} \\
& $(\mathbf{1})$ & $\mathbf{( 2 )}$ \\
\hline$E(\mathrm{HOMO})$ & -0.229 & -0.213 \\
$E($ LUMO $)$ & -0.054 & -0.053 \\
$\Delta E($ HOMO-LUMO $)$ & -0.175 & -0.160 \\
\hline
\end{tabular}

In the crystal structure of (1), the molecules are linked by intermolecular $\mathrm{C}-\mathrm{H} \cdots \pi$ interaction $[\mathrm{C} 15-\mathrm{H} 15 \mathrm{C} \cdots \mathrm{Cg} 3$ : H15C... Cg3: $2.980 \AA, x, 1+y, z]$ between the methyl hydrogen of imidazole ring and the centre of benzene ring with the bond distance of 3.667(2) $\AA$. In addition, the nitrile group makes $\mathrm{C}-\mathrm{N} \cdots \pi$ interaction [C7-N4 $\cdots$ Cg1: N4 $\cdots$ Cg1: $3.128(2) \AA, 1-x, 1-y, 1-z]$ to the centre of imidazole ring with the bond length of 3.752(2) $\AA$, where $\mathrm{Cg} 1$ and $\mathrm{Cg} 3$ are the centroids of N1-C1-C6-N2-C2, C8-C9-C10-C11-C12$\mathrm{C} 13$ rings, respectively (Figure $4(\mathrm{a})$ ). Moreover, weak $\pi-\pi$ intermolecular interactions [Cg1 ‥ Cg3; 4.916(14) $\AA$, $-x, 1-$ $y, 1-z$ for compound (1) and 3.507(3) $\AA, x, 1+y, z$ for compound (2), resp.] are observed and contribute to packing arrangement and stability.

3.4. Molecular Orbital Analysis. The HOMO-LUMO energy gap of a molecule will play a crucial role in deciding its bioactive properties and is a very important parameter for quantum chemistry. The HOMO energy distinguishes the capacity of electron donor, whereas LUMO energy characterizes the capacity of electron acceptor, and the gap distinguishes the chemical stability [20]. The HOMO-LUMO energy gap for the compounds (1) and (2) was calculated by 6$31 \mathrm{G}(\mathrm{TM})^{* *+}(6 \mathrm{D})$ basis set [20] and the values are $-0.175 \mathrm{a} . \mathrm{u}$ (1) and -0.160 a.u (2). The energies of HOMO and LUMO and the HOMO-LUMO energy gap are given in Table 4. The HOMO-LUMO orbital schemes of compounds (1) and (2) are 


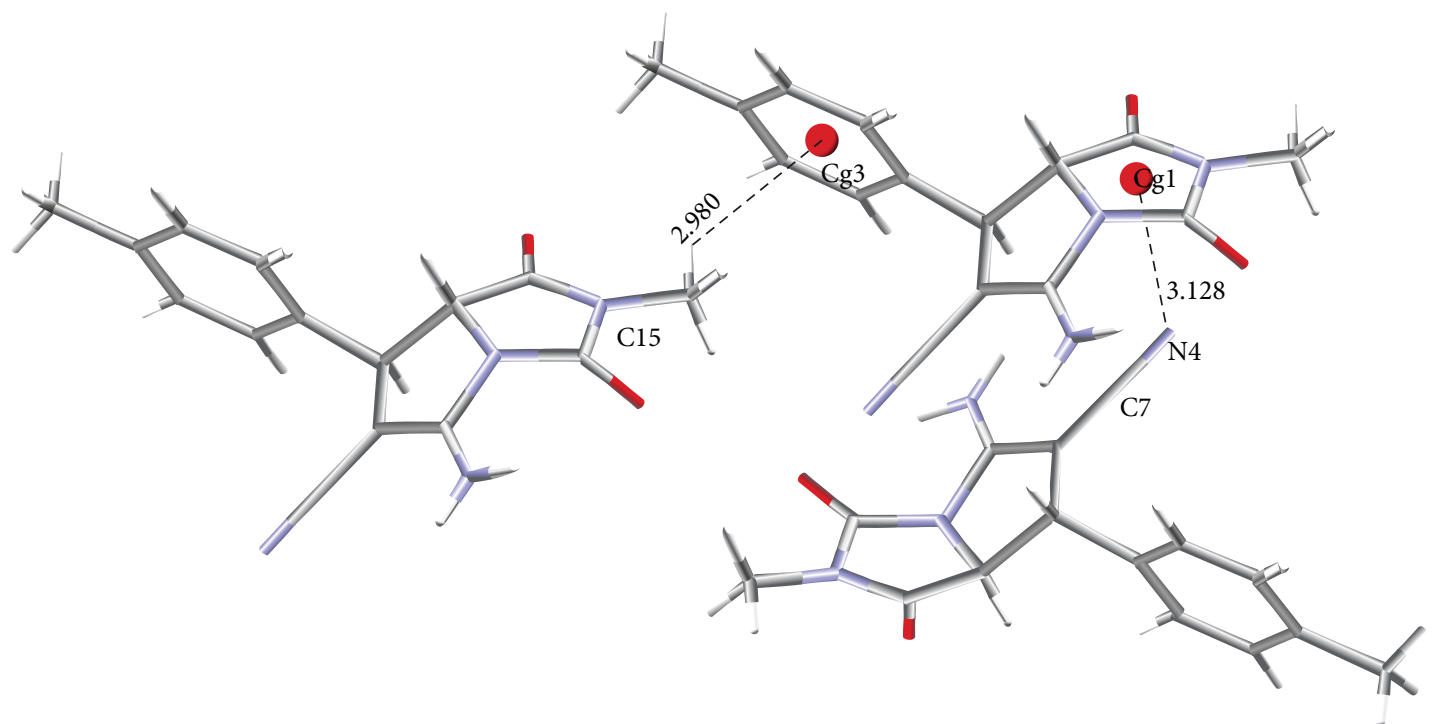

(a)

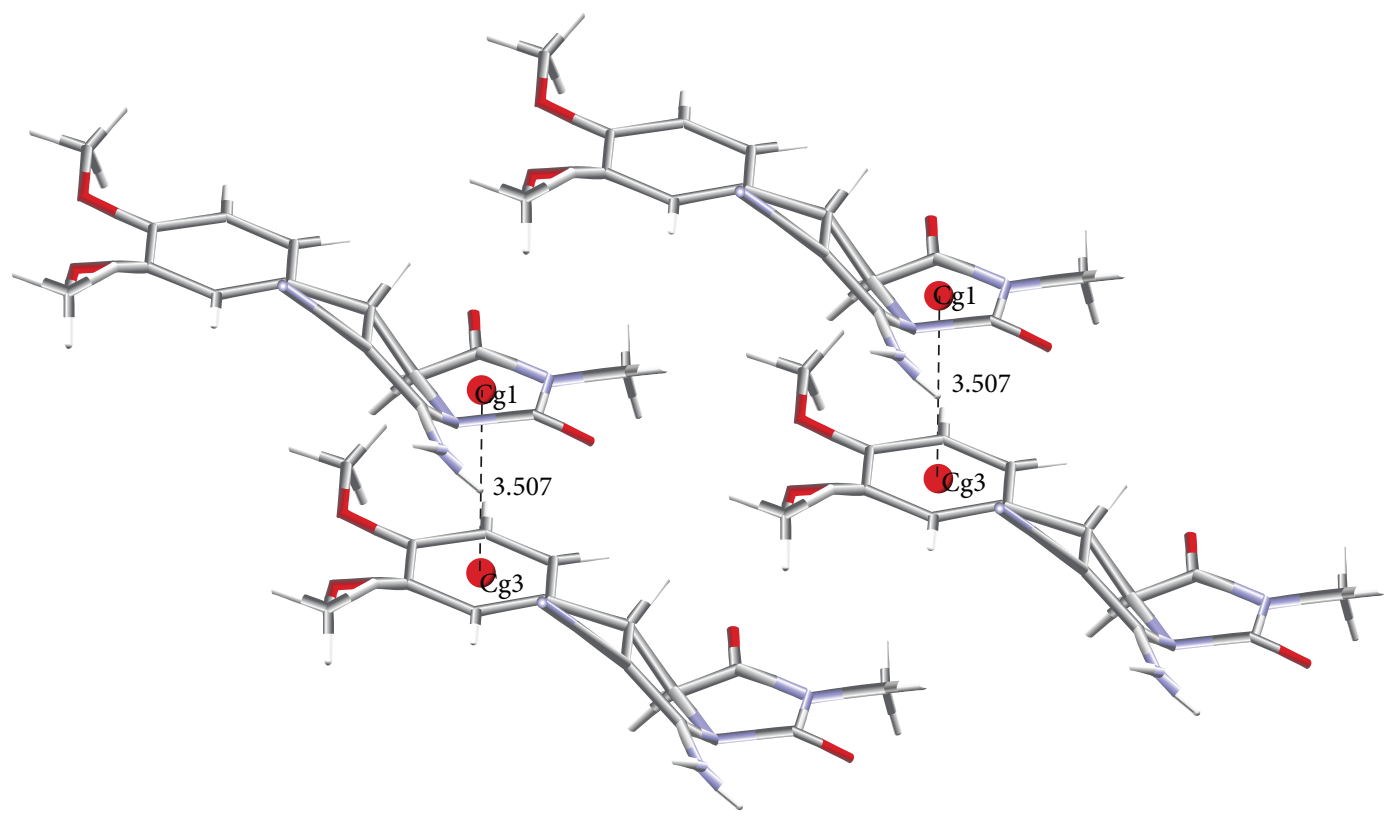

(b)

FIGURE 4: C-H $\cdots \pi$ and C-N $\cdots \pi$ interactions with a bond distance $(\AA)$ for compound (1) shown in (a) and $\pi-\pi$ interactions involved in compound (2) with their respective bond length $(\AA)$ shown in (b). [Cg1 = centroids of N1-C1-C6-N2-C2 ring and Cg3 = C8-C9-C10-C11C12-C13 ring].

shown in Figure 5 (positives phases are mentioned in red and the negatives ones in blue). The electron density of HOMO in compounds (1) and (2) shows that the HOMO is localized on fused Py-Im ring, methyl, and carbonyl groups. In case of LUMO, the electron density is localized on benzene ring only in compound (1) while in compound (2) the electron density is fully localized in carbonyl group and partially localized in benzene ring. The HOMO to LUMO transition signifies that an electron density transfers from fused $\mathrm{Py}-$ Im ring to benzene ring and the HOMO-LUMO energy gap $(-0.160 \mathrm{a} . \mathrm{u})$ in compound (2) is the smallest indicator that the molecule of compound (2) is more stable compared to compound (1). The HOMO to LUMO transition indirectly explains the descriptor of electron donor and acceptor in order to understand their interacting ability with their target molecules.

\section{Conclusions}

In the present study, we presented the structural details of fused Py-Im compounds, $\mathrm{C}_{15} \mathrm{H}_{15} \mathrm{~N}_{4} \mathrm{O}_{2}(1)$ and $\mathrm{C}_{16} \mathrm{H}_{16} \mathrm{~N}_{4} \mathrm{O}_{4}$ (2), by using single crystal X-ray diffraction data. DFT calculation was performed with standard $6-31 \mathrm{G}(\mathrm{TM})^{* *+}$ (6D) basis set to analyze the molecular geometry and 


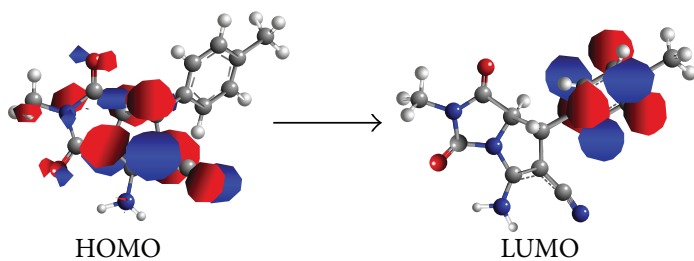

(a)

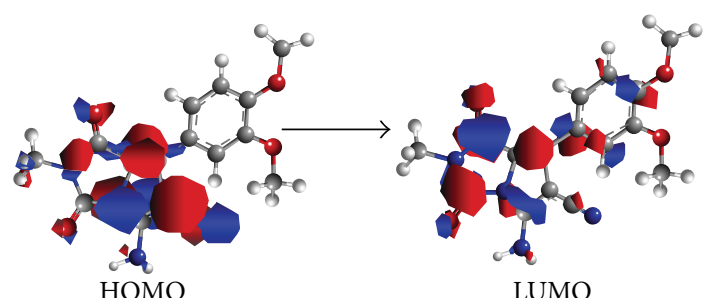

(b)

FIGURE 5: Atomic orbitals of HOMO to LUMO transition of the compounds (1) and (2) depicted in (a) and (b), respectively.

compared with experimentally available X-ray crystal data of compounds (1) and (2). The calculated HOMO-LUMO energy gap in compound (2) is -0.160 a.u and this small gap value indicates that compound (2) is chemically reactive compared to compound (1). Further, the crystal structure is stabilized by both intra- and intermolecular hydrogen bonds in which intermolecular $\mathrm{N}-\mathrm{H}$. . O hydrogen bond generates $\mathrm{C}_{1}{ }^{1}(6)$ and $\mathrm{C}_{1}{ }^{1}(7)$ chain motif in compounds (1) and (2), respectively. In addition, the packing is also stabilized by intermolecular $\mathrm{C}-\mathrm{H} \cdots \mathrm{O}, \mathrm{N}-\mathrm{H} \cdots \mathrm{N}$ hydrogen bonds and special type of interaction such as $\mathrm{C}-\mathrm{H} \cdots \pi, \mathrm{C}-\mathrm{N} \cdots \pi$, and $\pi-\pi$ interactions.

\section{Abbreviations}

Py-Im: Pyrroloimidazole

HOMO: Highest occupied molecular orbital

LUMO: Lowest unoccupied molecular orbital

p: $\quad$ Para.

\section{Conflict of Interests}

The authors have no conflict of interests with the mentioned commercial entity.

\section{Authors' Contribution}

Manikandan Jayaraman and Rajarathinam Balakrishnan contributed equally.

\section{Acknowledgments}

B. Rajarathinam and G. Vasuki thank CSIR (01(2500)/ 11/EMR-II Dt: 05.05.2011) and DST (SR/S5/GC-22/2007), Government of India, for financial support and the Department of Chemistry (DST-FIST), Pondicherry University, for FT-IR and single crystal XRD facilities. M. Kannan (No. F. 142(SC)/2009 (SA-III)) thanks UGC for Rajiv Gandhi National Fellowship for pursueing his Ph.D. degree. R. Krishna also thanks Department of Biotechnology and Department of Information Technology, Government of India, New Delhi, for the financial support to Centre for Bioinformatics, Pondicherry University.

\section{References}

[1] D. O’Hagan, "Pyrrole, pyrrolidine, pyridine, piperidine and tropane alkaloids," Natural Product Reports, vol. 17, no. 5, pp. 435-446, 2000.

[2] X. Wu, S. Toppet, F. Compernolle, and G. J. Hoornaert, "Generation of cyclopenta[c]piperidines and pyrrolo[3,4-c]piperidines-potential substance $\mathrm{P}$ antagonists-from adducts of cyclic dienophiles and 5-chloro-6-methyl-3-phenyl-2H-1,4oxazin-2-one," Tetrahedron, vol. 56, no. 34, pp. 6279-6290, 2000.

[3] R. Tamazyan, H. Karapetyan, A. Martirisyan, V. Martirosyan, G. Harutyunyan, and S. Gasparyan, "1,2,5-substituted derivatives of 2-phenylpyrrolidine," Acta Crystallographica C: Crystal Structure Communications, vol. 60, part 6, pp. o390-o392, 2004.

[4] X. E. Hu, N. K. Kim, J. L. Gray, J. K. Almstead, W. L. Seibel, and B. Ledoussal, "Discovery of (3S)-amino-(4R)-ethylpiperidinyl quinolones as potent antibacterial agents with a broad spectrum of activity and activity against resistant pathogens," Journal of Medicinal Chemistry, vol. 46, no. 17, pp. 3655-3661, 2003.

[5] S. Thamotharan, V. Parthasarathi, P. Gupta, D. P. Jindal, P. Piplani, and A. Linden, "N-(2-naphthyloxymethylcarbonyl)pyrrolidine," Acta Crystallographica E: Structure Reports Online, vol. 59, no. 9, pp. o1334-o1335, 2003.

[6] J. Cheng, J. Xie, and X. Luo, "Synthesis and antiviral activity against Coxsackie virus B3 of some novel benzimidazole derivatives," Bioorganic and Medicinal Chemistry Letters, vol. 15, no. 2, pp. 267-269, 2005.

[7] A. T. Mavrova, K. K. Anichina, D. I. Vuchev et al., "Antihelminthic activity of some newly synthesized 5(6)-(un)substituted1 H-benzimidazol-2-ylthioacetylpiperazine derivatives," European Journal of Medicinal Chemistry, vol. 41, no. 12, pp. 14121420, 2006.

[8] S. Laufer and P. Koch, "Towards the improvement of the synthesis of novel 4(5)-aryl-5(4)-heteroaryl-2-thio-substituted imidazoles and their p38 MAP kinase inhibitory activity," Organic and Biomolecular Chemistry, vol. 6, no. 3, pp. 437-439, 2008.

[9] L. R. Roberts, P. V. Fish, R. Ian Storer, and G. A. Whitlock, “6,7Dihydro-5H-pyrrolo[1,2-a] imidazoles as potent and selective $\alpha 1 \mathrm{~A}$ adrenoceptor partial agonists," Bioorganic and Medicinal Chemistry Letters, vol. 19, no. 11, pp. 3113-3117, 2009.

[10] B. Rajarathinam and G. Vasuki, "Diastereoselective multicomponent reaction in water: synthesis of 2-azapyrrolizidine alkaloid analogues," Organic Letters, vol. 14, no. 20, pp. 52045206, 2012.

[11] G. M. Sheldrick, "A short history of SHELX," Acta Crystallographica A: Foundations of Crystallography, vol. 64, no. 1, pp. 112-122, 2007. 
[12] Oxford Diffraction CrysAlis CCD, CrysAlis RED and CrysAlis PRO, Oxford Diffraction, Yarnton, UK, 2009.

[13] L. J. Farrugia, "ORTEP-3 for windows-a version of ORTEPIII with a graphical user interface (GUI)," Journal of Applied Crystallography, vol. 30, no. 5, p. 565, 1997.

[14] A. L. Spek, "Structure validation in chemical crystallography," Acta Crystallographica D: Biological Crystallography, vol. 65, part 2, pp. 148-155, 2009.

[15] C. F. Macrae, P. R. Edgington, P. McCabe et al., "Mercury: visualization and analysis of crystal structures," Journal of Applied Crystallography, vol. 39, no. 3, pp. 453-457, 2006.

[16] F. H. Allen, O. Kennard, D. G. Watson, L. Brammer, A. G. Orpen, and R. Taylor, "Tables of bond lengths determined by $\mathrm{x}$-ray and neutron diffraction, part 1 : bond lengths in organic compounds," Journal of the Chemical Society, Perkin Transactions 2, no. 12, pp. S1-S19, 1987.

[17] M. W. Schmidt, K. K. Baldridge, J. A. Boatz et al., "General atomic and molecular electronic structure system," Journal of Computational Chemistry, vol. 14, no. 11, pp. 1347-1363, 1993.

[18] D. Cremer and J. A. Pople, "A general definition of ring puckering coordinates," Journal of the American Chemical Society, vol. 97, no. 6, pp. 1354-1358, 1975.

[19] J. Bernstein, R. E. Davis, L. Shimoni, and N. Chang, "Patterns in hydrogen bonding: functionality and graph set analysis in crystals," Angewandte Chemie (International Edition), vol. 34, no. 15, pp. 1555-1573, 1995.

[20] X. T. S. Xavier.t.s and I. H. Joe, "FT-IR, Raman and DFT study of 2-amino-5-fluorobenzoic acid and its biological activity with other halogen $(\mathrm{Cl}, \mathrm{Br})$ substitution," Spectrochimica Acta A: Molecular and Biomolecular Spectroscopy, vol. 79, no. 2, pp. 332337, 2011. 

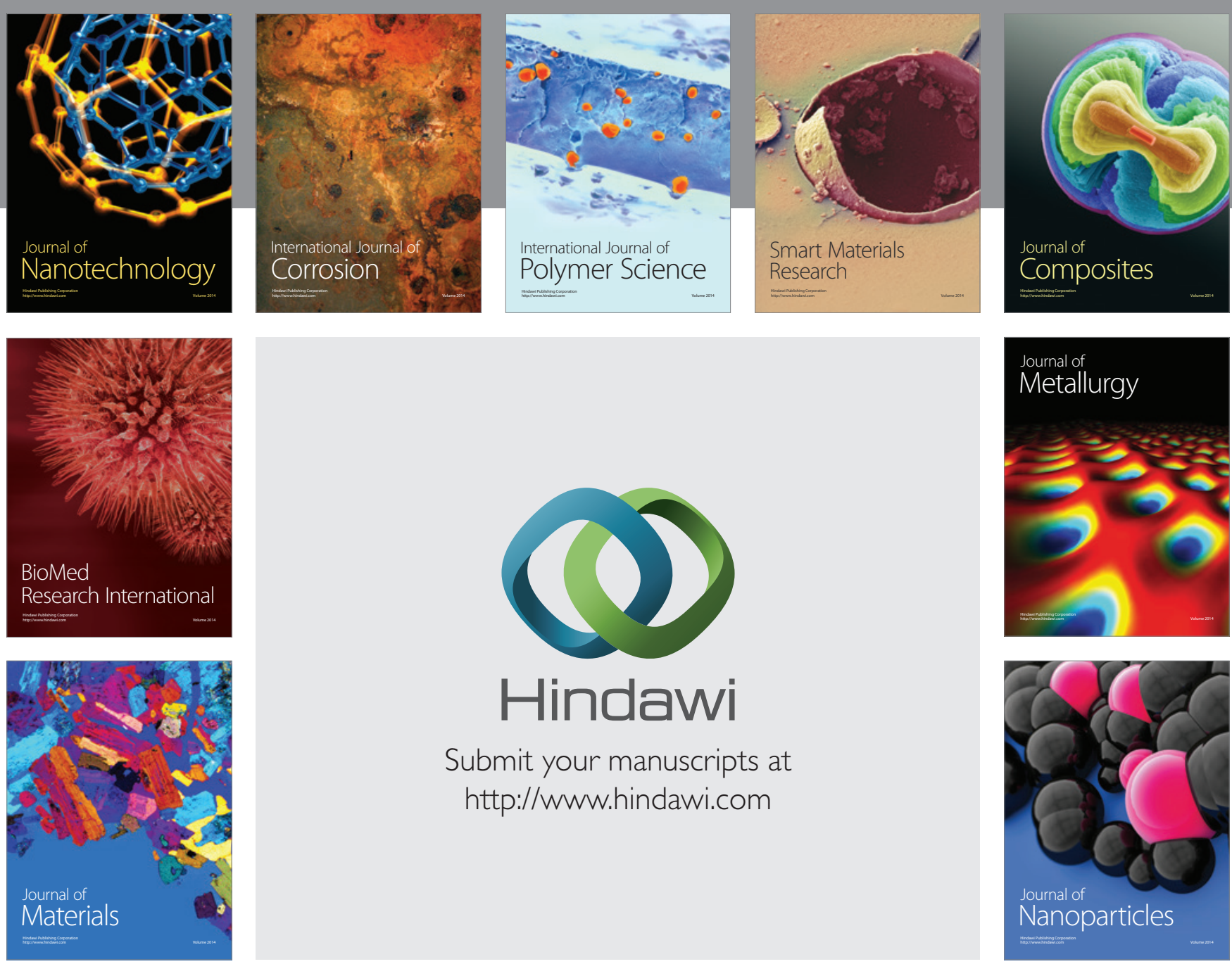

Submit your manuscripts at http://www.hindawi.com
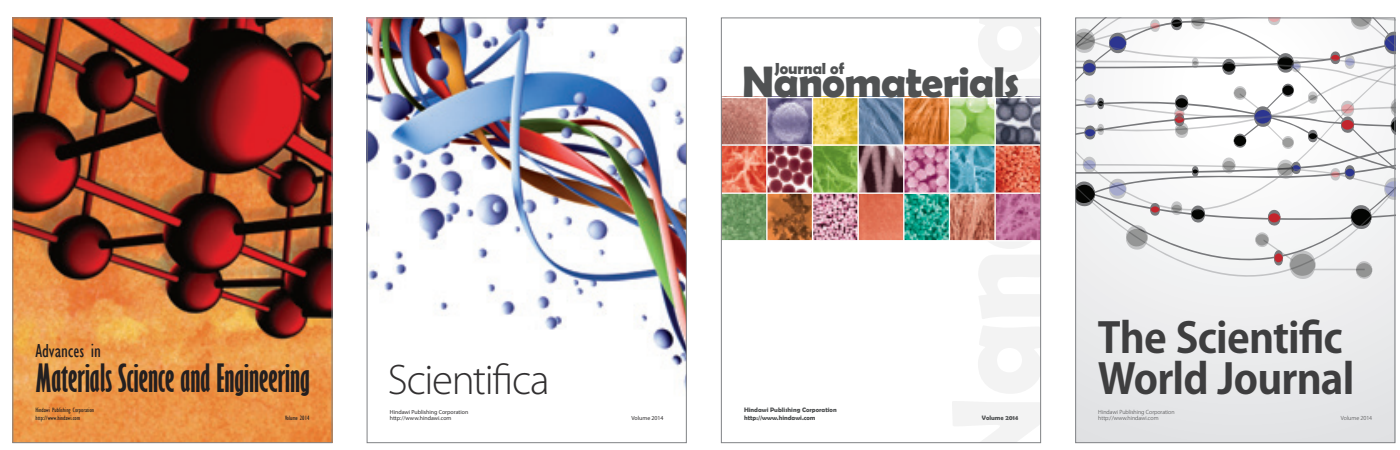

\section{The Scientific World Journal}
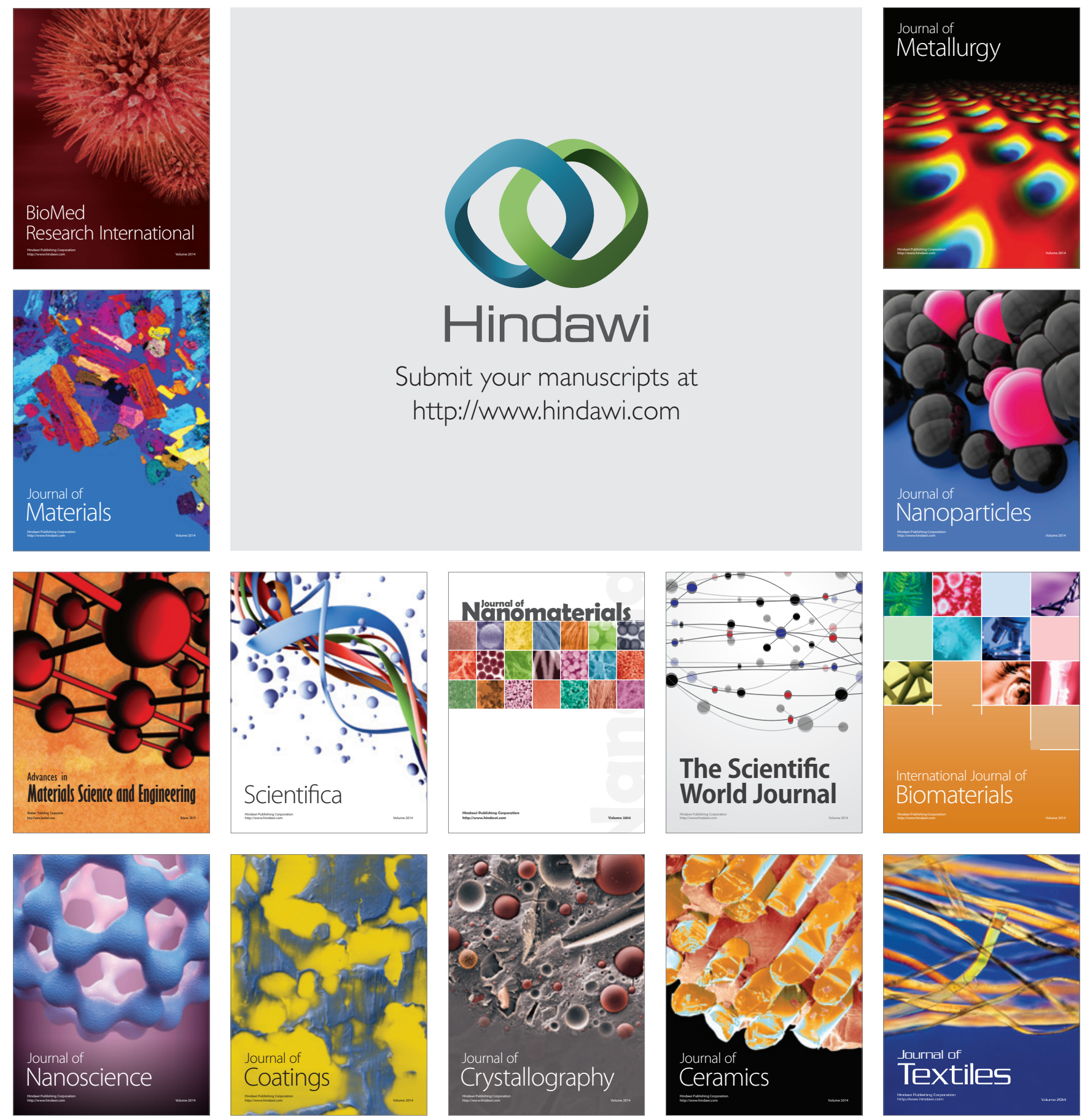